contract; one private and one NHS. Both approached us independently suggesting they subcontract SPCT to the hospice.

Aims Hospice to employ SPCT under terms of two separate subcontracts, one private, one NHS, ensuring patients and families receive seamless care wherever they are.

Methods Sub-contract required Board approval, considering risks and benefits to hospice reputation, including public perception of hospice 'funding' private healthcare. Learning curve for Directors in projecting five year costings with no knowledge of current costs, ensuring no financial risk to charity, and legalities around contracts.

Results Agreeing the specification and quality data was time consuming. Numerous bureaucratic executive layers through which to proceed for approval, and efforts to ensure that the service was fully funded for the duration of the subcontract to avoid risk to charity.

Conclusion A year later the SPCT fully integrated in hospice with no financial risk to charity as fully funded. Hospice corporate uniform supplied so visible immediately as hospice employee, all one team raises awareness for income generation. Ability to be creative with roles and working patterns ensuring seven day clinical and admin cover, and implementation of development roles within team.

\section{P-236 INCREASING CYBER SECURITY AWARENESS IN THE HOSPICE ENVIRONMENT}

Tim Clifton. St Helena Hospice, Colchester, UK

10.1136/bmjspcare-2018-hospiceabs.261

Background The weakest link in a company's cyber security are employees (Belbey, 2015). Rather than spending money on expensive software and hardware based solutions we decided to focus our efforts where we would make the most difference - the end user.

Aims To increase employees' cyber security knowledge to reduce the likelihood of them and the hospice becoming a victim of cyber security incidents.

Method Jan to Feb 2017: Evaluation of training delivery methods - eLearning was chosen. Research on costs and providers. March to May 2017: Cost of buying in training was prohibitive, so decision made to offer to create training and offer the intellectual property to our existing eLearning provider if they would produce and wrap this training. We could utilise the training in our preferred format, and they would benefit from selling this nationally. June 2017 to October 2017: Head of IT is approved as a subject matter expert and creates a two-hour training course which is produced by national eLearning provider and officially accredited by independent external agencies. November 2017: Course is officially released and available as one of the eLearning provider's online courses.

Results Between December 2017 and Mid May 2018, the Cyber Security Awareness (both standard user and line manager editions) have been undertaken with the knowledge check test being passed 320 times by both staff and volunteers. Random simulated phishing testing showed $25 \%$ of people had opened these e-mails with $5 \%$ clicking on the links within them.
Conclusion Evaluation of the cyber security training in-house has shown a positive response from those who have undertaken it and the manner of its delivery has enabled end users to undertake the training at times best suited to them. The delivery method has also saved hours of IT time in that no face-to-face sessions were delivered.

\section{P-237 TOWARDS A LEADERSHIP MODEL AND 360 APPRAISAL FROM THE PERSPECTIVE OF THOSE WHO ARE LED}

John Procter, Roger Noon. Garden House Hospice Care, Letchworth Garden City, Hertfordshire

\subsection{6/bmjspcare-2018-hospiceabs.262}

Need The Chairman of Trustees of Garden House Hospice Care decided to explore whether it was possible to devise a more bespoke and developmental means of performing a 360 appraisal for the CEO. An innovative new approach was developed based on the repertory grid method (Kelly, 1963; Fransella \& Bannister, 1977) and informed by personal construct theory (Kelly, 1963).

Approach The project first created a leadership model based on the personal constructs of those interviewed during the 360 process. Whilst the feedback was anonymised and the interviews confidential, the leadership model that emerged could be shared. Since the 360 appraisal participants included Board members, external stakeholders, other senior leaders and more junior members of the organisation, this model was effectively a synthesised view of the characteristics of leadership considered to be important in the hospice.

The Repertory Grid Method This is a well-established means of eliciting a person's understanding of leadership by generating a set of their personal 'constructs'. Once the constructs were elicited, the participants assessed the CEO against them, providing a view of performance based on the areas that were most important to them. This assessment was backed up with reference to specific experiences and examples.

Conclusions The project concluded that this approach provided a richer understanding of how leadership is experienced from a variety of people's perspectives. The final report gave a broader and deeper view of the leadership characteristics demonstrated by the CEO, how well others felt she demonstrated them and how much these characteristics were valued. In addition a bespoke model of leadership has been produced that has high relevance to staff. Internal resources can now be trained to elicit feedback for further appraisals against a common model and the model itself will continually evolve as more people contribute to it.

\section{P-238 GIVING COLLEAGUES A VOICE: ESTABLISHING A MEANINGFUL COLLEAGUE REPRESENTATIVE GROUP}

Sarah Pugh. Heart of Kent Hospice, Aylesford, UK

10.1136/bmjspcare-2018-hospiceabs.263

Background In the hospice's 2016 Colleague Survey, 45\% of respondents stated 'communication between colleagues and the senior team is effective'; $30 \%$ disagreed. $58 \%$ of respondents 